\title{
Professor auxiliar e a inclusão de alunos com Transtorno do Espectro Autista
}

\section{Assistant pand the inclusion of students with Autism Spectrum Disorder \\ Profesor auxiliar y una inclusión de alumnos con Trastorno del Espectro Autista}

\section{* Paulo César Morales Mayer ${ }^{1}$}

Professor doutor na Universidade CEUMA, Imperatriz, Maranhão, Brasil. paulocmayer@gmail.com - http://orcid.org/0000-0001-9484-2118

\section{${ }^{* *}$ Marta Angélica lossi Silva}

Professora doutora na Universidade de São Paulo, Ribeirão Preto, São Paulo, Brasil. maiossi@eerp.usp.br

\section{*** Reinaldo Antonio Silva-Sobrinho}

Professor doutor na Universidade Estadual do Oeste do Paraná, Foz do Iguaçu, Paraná, Brasil. reisobrinho@yahoo.com.br - http://orcid.org/0000-0003-0421-4447

\section{**** Rosane Meire Munhak da Silva}

Professora doutora na Universidade Estadual do Oeste do Paraná, Foz do Iguaçu, Paraná, Brasil. zanem2010@hotmail.com - http://orcid.org/0000-0003-3355-0132

\section{***** Adriana Zilly}

Professora doutora na Universidade Estadual do Oeste do Paraná, Foz do Iguaçu, Paraná, Brasil. aazilly@hotmail.com - https://orcid.org/0000-0002-8714-8205

Recebido em 10 de junho de 2018

Aprovado em 25 de maio de 2019

Publicado em 03 de julho de 2019

\section{RESUMO}

No Brasil, é direito do aluno com Transtorno do Espectro Autista (TEA), com comprovadas necessidades, ter a presença de um acompanhante especializado em sala de aula, o professor auxiliar; contudo, a legislação relativa a esse profissional é recente. O presente estudo caracterizou esses profissionais e sua percepção sobre suas atividades mediante a entrevista de 12 acompanhantes especializados da cidade de Foz do Iguaçu, Paraná. Os dados da caracterização foram tabulados e os dados qualitativos analisados pelo método do Discurso do Sujeito Coletivo. Todos os entrevistados eram do sexo feminino, com média de idade de 37 anos, três tinham pós-graduação em educação especial e oito estavam

\footnotetext{
1 O presente estudo é derivado da pesquisa de pós-doutorado do primeiro autor sob orientação do último autor e for parcialmente financiado pela bolsa do programa nacional de pós-doutorado (PNPD-CAPES edital: 086/2013, processo: 1544183) concedida ao primeiro autor.
} 
tendo sua primeira experiência em educação especial na atividade atual. Nos discursos desses profissionais, observou-se conhecimentos limitados sobre o autismo, pouca articulação com o professor regente, necessidade de capacitações com atividades práticas e um misto de frustrações e realizações pessoais em relação à atuação. Pontua-se que a atividade do professor auxiliar ainda está em desenvolvimento, poucos estudos relatam essa atuação e ainda há necessidade de normativas específicas delimitando seus requisitos profissionais, abrangência e metas educacionais.

Palavras-chave: Educação Especial; Autismo; Inclusão educacional.

\section{ABSTRACT}

In Brazil, every student diagnosed with Autism Spectrum Disorder (ASD), with recognized needs, has the right of an assistant in the classroom. The legislation regarding this professional is recent though. The present study described the characteristics of these professionals, and their perspective on the activities they perform. Twelve teacher assistants from Foz do lguaçu, PR, were interviewed. The characterization data were tabulated and qualitative data were analyzed according to the Collective Subject Discourse method. All 12 interviewees were female, only three had graduate degree in special education, the mean age was 37 years, and eight teachers were having their first experience in special education in their current activity. In the speeches we observe diversity of educational background, only three assistants had academic degree in special education, limited knowledge about autism, little articulation between the assistant and the regular teacher, need for training in practical activities and a mixture of frustrations and personal realizations about their actions. The teacher assistant activity is still being established, there are few studies in Brazil about it. This study highlights the need for specific norms stablishing their professional credentials as well as the scope and educational aims of their intervention. Keywords: Special Education; Autism; Educational Inclusion.

\section{RESUMEN}

En Brasil, es derecho del alumno con Trastorno del Espectro Autista (TEA), con comprobadas necesidades, tener la presencia de un acompañante especializado en el aula, el profesor auxiliar. Sin embargo, la legislación relativa a este profesional es reciente. El presente estudio apunta a caracterizar a estos profesionales y conocer la percepción de éstos sobre sus actividades. Se entrevistaron a 12 acompañantes especializados de Foz do Iguaçu, Paraná. Los datos de la caracterización fueron tabulados y los datos cualitativos fueron analizados según el método del Discurso del Sujeto Colectivo. Se constató que todos los 12 entrevistados eran del sexo femenino, apenas 03 con post graduación en educación especial, promedio de edad de 37 años y 08 profesoras estaban teniendo su primera experiencia en su actividad actual. En los discursos observamos conocimientos limitados sobre autismo, poca articulación con el maestro regente, necesidad de capacitaciones con actividades prácticas y una mezcla de frustraciones y realizaciones personales en relación a la actuación. La actividad del profesor auxiliar aún está en desarrollo, pocos estudios relatan esa actuación y necesitan de una normativa específica delimitando sus requisitos profesionales, alcance y metas educativas. 
Palabras clave: Educación Especial; autismo; Inclusión educativa Introdução

O Transtorno do Espectro Autista (TEA), ou autismo, caracteriza-se por déficits de interação social, comprometimento da linguagem, estereotipia comportamental e interesses restritos (APA, 2014). Tais características podem ser acompanhadas de limitações cognitivas a depender do grau de comprometimento e comorbidade (SCHMIDT, 2017).

Embora o autismo seja uma condição limitante do desenvolvimento e não tenha "cura", intervenções precoces, intensivas e multiprofissionais, podem amenizar os comprometimentos, permitindo, inclusive, que o indivíduo autista, leve uma vida autônoma produtiva e com qualidade (WARREN et al., 2011). Dentre as atividades necessárias para um desenvolvimento adequado e uma vida autônoma, a escolaridade bem sucedida é um dos elementos fundamentais (KEEN; WEBSTER; RIDLEY, 2016).

Gobbo, Bonfiglio e Schwartz (2016) ressaltam que um grande avanço para a inclusão escolar dos alunos com necessidades especiais ocorreu com a atual Lei de Diretrizes e Bases da Educação (LDB) de 1996. Posteriormente a essa Lei, os principais documentos que garantem os direitos educacionais de indivíduos autistas no Brasil são: 1) a Política Nacional de Educação Inclusiva (BRASIL, 2008), a qual afirma o direito de o aluno autista ser matriculado em salas de ensino regular em todos os níveis educacionais; 2) a Lei no. 12.764/12, também conhecida como Lei Berenice Piana, que estabelece a Política Nacional de Proteção dos Direitos da Pessoa com Transtorno do Espectro Autista e assegura o direito de um acompanhante especializado em sala de aula em caso de comprovada necessidade (BRASIL, 2012); e 3) o Decreto №. 8.368/14, que regulamenta a Lei №. 12.764/12 e salienta a obrigatoriedade da instituição de ensino em providenciar esse profissional, quando devidamente solicitado (BRASIL, 2014).

Salienta-se que essas leis seguem uma tendência mundial no sentido de oferecer melhores condições às pessoas portadoras de necessidades especiais. Além de combaterem a exclusão social e preconceito em relação ao indivíduo autista, visam ao seu efetivo aprendizado a partir de adaptações pedagógicas compatíveis com suas necessidades.

Segundo o levantamento de Bertazzo (2014), a prática de acompanhamento de pessoas com necessidades especiais ganhou destaque na década de 1960 em movimentos de desinstitucionalização. Entretanto, no contexto escolar, em especial no Brasil, essa 
prática está ainda em construção. Dentre as diversas denominações e funções do acompanhante escolar encontradas por este autor sobressai o papel de mediador das relações entre o aluno e o meio escolar, sejam com colegas, professores ou funcionários, além de questões relacionadas à aprendizagem e à promoção de autonomia do aluno.

Nunes, Azevedo e Schmidt (2013) realizaram uma revisão da literatura nacional dos estudos de inclusão escolar de alunos autistas, no período de 2008 e 2012, e identificaram resultados promissores na escolarização de indivíduos autistas quando havia maior colaboração entre educadores da escola regular e da escola especial em atendimento simultâneo e com acompanhante terapêutico ou professor auxiliar. No entanto, estes autores salientam a necessidade de uma formação e supervisão adequadas para esses profissionais, os quais, por vezes, são apenas estudantes de Ensino Médio cumprindo meramente o papel de cuidadores. Outros autores como Padilha (2013), Haas et al. (2016) e Dias (2017) corroboram a importância da interação/colaboração entre os educadores envolvidos no processo de inclusão.

Apesar da relevância do professor auxiliar, identificada em diferentes estudos, sua participação no ensino de alunos autistas é um direito recente; além disso, não há demarcação clara das exigências de formação ou do papel desse profissional nas atividades educacionais e pedagógicas.

Nesse sentido, no presente estudo objetiva-se caracterizar os professores auxiliares no município de Foz do Iguaçu, PR e conhecer a percepção destes a respeito de sua atuação.

\section{Método}

Trata-se de um estudo transversal e exploratório, de natureza qualiquantitativa, baseado no referencial teórico da análise do Discurso do Sujeito Coletivo (DSC) de Lefevre e Lefevre (2012). Tal perspectiva deriva da teoria de representação social, a qual considera a comunicação como um meio simbólico partilhado por indivíduos de uma mesma cultura, composta tanto pelos seus símbolos linguísticos quanto por um código ideológico repleto de valores e crenças pessoais e coletivas.

A característica central do DSC é a preservação da essência e profundidade do método qualitativo ao trabalhar com discursos ao invés de respostas fechadas, adicionando a estes um elemento quantitativo ao trabalhar com a síntese de discursos, opiniões e argumentos em comum apresentados por diferentes indivíduos. Esse método permite maior 
generalização dos dados por identificar uma perspectiva coletiva da população estudada em relação ao fenômeno abordado (LEFEVRE; LEFEVRE, 2012).

\section{Participantes}

A população do estudo foi composta de 12 professores auxiliares ${ }^{2}$ da rede municipal de ensino da cidade de Foz do Iguaçu, PR. O critério de inclusão era ser professor auxiliar desse município, de pelo menos um aluno diagnosticado com autismo. Por questões éticas, foram excluídos do grupo de sujeitos participantes, professores com idade inferior a 18 anos. A coleta de dados foi conduzida entre os meses de setembro e outubro de 2016.

\section{Material}

Foi utilizado um roteiro de entrevista, semiestruturado, com questões relativas à caracterização dos participantes e questões abertas envolvendo temas relativos aos conhecimentos do professor sobre o autismo, a inserção do professor na atividade que exerce e sua relação com o professor regente.

\section{Local}

A pesquisa foi realizada em oito escolas da rede municipal de ensino de um município do Estado do Paraná, Foz do Iguaçu. O município conta com 51 escolas públicas de ensino fundamental I ( $1^{\circ}$ ao 5o ano), com registro de 18.374 matrículas em 2016. É meta, traçada no plano municipal de educação do município, universalizar acesso à educação básica para alunos autistas entre 4 e 17 anos de idade, com atendimento educacional especializado, priorizando sua permanência na rede regular de ensino.

\section{Procedimentos}

Em contato com a Secretaria Municipal da Educação do município de Foz do Iguaçu, $\mathrm{PR}$, foi identificado um total de 22 professores auxiliares atuantes com alunos autistas, alocados em 15 escolas. Após contato com as escolas, verificou-se que 14 professores continuavam atuando em oito escolas; destes, dois eram estagiários do magistério com idade inferior a 18 anos e não foram incluídos no estudo. Através de contato por telefone com a diretora de cada escola, foi agendado um horário para apresentação dos objetivos do projeto, verificação do interesse da escola em participar do estudo e contato com o

\footnotetext{
${ }^{2}$ Como no município estudado o acompanhante especializado era denominado professor auxiliar, essa foi a nomenclatura adotada neste estudo.
} 
professor para realização das entrevistas. Todas as escolas contatadas, que possuíam aluno autista matriculado e professor auxiliar atuando em sala de aula, demonstraram interesse em participar do estudo. Do mesmo modo, todos os professores auxiliares contatados aceitaram participar da entrevista e autorizaram gravação em áudio. Um total de 12 entrevistas foram realizadas.

As entrevistas duraram, em média, 30 minutos (variando de 15 a 62 min.) e foram conduzidas em uma sala reservada, concedida pela direção de cada escola, permanecendo no local apenas o professor entrevistado e o entrevistador a fim de possibilitar um ambiente acolhedor e privativo. Todas entrevistas foram conduzidas e transcritas na íntegra pelo primeiro autor.

\section{Análise de Dados}

$\mathrm{Na}$ trajetória analítico-interpretativa dos dados, o conteúdo das entrevistas foi categorizado de acordo com os temas de interesse (i.e. autismo, educação especial, inclusão escolar, trajetória profissional) e as falas dos participantes analisadas pelo método do Discurso do Sujeito Coletivo (DSC) de Lefevre e Lefevre (2012).

Tal método visa agrupar, em discursos-síntese, o conteúdo de percepções e opiniões partilhadas por diferentes sujeitos pertencentes a um determinado coletivo a respeito de temas específicos abordados nas entrevistas. Uma vez obtidas as falas individuais pela entrevista, é preciso tratar esses dados a fim de que possam expressar a voz da coletividade. Quantificar a frequência com que certas partes do texto se fazem presentes no discurso é uma forma de qualificá-lo e classificá-lo (LEFEVRE; LEFEVRE, 2012). Para isso, o DSC possui algumas ferramentas metodológicas: Expressões-Chave $(\mathrm{ECH})$; as Ideias Centrais (Ics); as Ancoragens (Acs) e o Discurso do Sujeito Coletivo (DSC), propriamente dito. A utilização desse método permite a identificação de um pensamento coletivo; assim, cada indivíduo expõe seu pensamento social internalizado e o conjunto dessas individualidades opinantes representa uma coletividade, estabelecendo a relação social (LEFEVRE; LEFEVRE, 2006).

A partir da transcrição das entrevistas, foram extraídos, das falas de cada participante, os temas e as expressões-chave referentes a cada assunto que se relacionavam à uma ideia central, partilhada por diferentes indivíduos, e destacado o trecho da fala correspondente. As falas de cada participante foram então agrupadas de acordo com a compatibilidade das expressões chaves e falas que expressavam uma mesma ideia central 
e sintetizadas em discursos pontuais, contendo trechos representativos. Tanto a extração quanto a construção das ideias centrais foram realizadas pelo primeiro autor do estudo e revisadas pelos demais autores.

\section{Aspectos Éticos}

O presente estudo foi aprovado no Comitê de Ética em Pesquisas com Seres Humanos da Unioeste de Cascavel-PR, parecer nํㅜ 1.665.147.

\section{Resultados}

\section{Caracterização da população}

A Tabela 1 apresenta as características das 12 participantes, todas do sexo feminino. No tocante à formação, uma professora possui ensino superior completo e as demais ( $n=11)$, especialização ou mestrado, sendo três em áreas relacionadas à educação especial ou inclusão escolar, além de duas professoras estagiárias do magistério não incluídas no estudo por terem idade inferior a 18 anos.

A idade média das entrevistadas era de 37 anos, variando de 22 a 55 , sendo $50 \%$ com idade inferior a 40 anos. Quanto à experiência profissional, quatro professoras tinham mais de 20 anos de experiência especificamente com educação especial, oito professoras estavam tendo sua primeira experiência na atividade atual.

\section{Inserção como professor auxiliar}

Em relação à forma da inserção dos professores como auxiliares de aluno autista, em dois casos a prefeitura indicou o profissional devido à falta de pessoal na escola, sendo duas estagiárias que estavam cursando o magistério. Nos demais casos, as professoras exerceram a atividade simplesmente pelo acaso de ser a vaga disponível no momento. Os DSCs do Quadro 1 ilustram a descrição das professoras de sua convocação a serem professoras auxiliares. 
Tabela 1 - Caracterização dos professores auxiliares atuantes no município pesquisado, listados em ordem crescente a partir da idade, Foz do Iguaçu, 2016

\begin{tabular}{|l|l|l|l|l|l|l|}
\hline PARTICIPANTE & SEXO & IDADE & FORMAÇÃO & PROFESSOR & $\begin{array}{l}\text { TEMPO } \\
\text { ATUAÇÃo } \\
\text { ED. ESPECI }\end{array}$ & TEA \\
\hline P1 & Fem. & 22 & Ensino Superior & 3 anos & 7 meses & 7 meses \\
\hline P2 & Fem. & 25 & Especialização* & 3 anos & 3 semanas & 3 semanas \\
\hline P3 & Fem. & 25 & \multicolumn{1}{|c|}{ Especialização } & 15 anos & 4 anos & 4 meses \\
\hline P4 & Fem. & 28 & Especialização & 10 anos & 2 anos & 2 meses \\
\hline P5 & Fem. & 30 & Especialização & 6 anos & 1 mês & 1 mês \\
\hline P6 & Fem. & 36 & Especialização & 17 anos & 9 meses & 9 meses \\
\hline P7 & Fem. & 37 & Especialização & 10 anos & 1 mês & 1 mês \\
\hline P8 & Fem. & 42 & $\begin{array}{l}\text { Especialização } \\
\text { (Andamento) }\end{array}$ & 6 anos & 2 anos & 2 anos \\
\hline P9 & Fem. & 49 & Especialização & 20 anos & 8 anos & 2 meses \\
\hline P10 & Fem. & 51 & Mestrado & 27 anos & 5 meses & 5 meses \\
\hline P11 & Fem. & 52 & Especialização & 21 anos & 4 anos & 2 anos \\
\hline P12 & Fem. & 55 & Mestrado & 33 anos & 3 meses & 3 meses \\
\hline
\end{tabular}

* indica formação relacionada à educação especial ou inclusão escolar.

Fonte: Autores.

Quadro 1- Ideias Centrais e Discursos do Sujeito Coletivo referente ao motivo da inserção da profissional como professor auxiliar, Foz do Iguaçu, 2016

\begin{tabular}{|l|l|}
\hline \multicolumn{1}{|c|}{ IC } & \multicolumn{1}{c|}{ DSC } \\
\hline Concurso & $\begin{array}{l}\text { "Assumi o concurso, na verdade foi uma necessidade da escola, } \\
\text { precisavam do professor de apoio". }\end{array}$ \\
\hline Afastamento & $\begin{array}{l}\text { "Estava afastada e precisavam de professor auxiliar quando voltei da } \\
\text { licença". }\end{array}$ \\
\hline Transferência & $\begin{array}{l}\text { "Eu pedi transferência de uma escola que eu trabalhava e fui para } \\
\text { outra". }\end{array}$ \\
\hline $\begin{array}{l}\text { Ampliação de de } \\
\text { carga horária }\end{array}$ & $\begin{array}{l}\text { "Surgiu a oportunidade, como eu queria dobrar a carga horária, deu } \\
\text { certo". }\end{array}$ \\
\hline
\end{tabular}

Fonte: Autores.

\section{Instruções de atuação}

Quando questionadas acerca das instruções que receberam da direção ou da coordenação da escola sobre sua atuação como professor auxiliar, dois discursos puderam ser identificados: um apontando o caráter vago e com instruções genéricas e outro no qual eram apenas fornecidas informações referentes aos alunos que teriam de acompanhar (Quadro 02)

Quadro 2- Ideias Centrais e Discursos do Sujeito Coletivo referente às instruções recebidas sobre a atividade de professor auxiliar, Foz do Iguaçu, 2016

\begin{tabular}{|l|l|}
\hline \multicolumn{1}{|c|}{ IC } & \multicolumn{1}{c|}{ DSC } \\
\hline Instruções & "Mostrou que a inclusão está amparada pela lei e que eu teria liberdade de \\
genéricas & trabalhar com a criança." \\
\hline $\begin{array}{l}\text { Apenas } \\
\text { informações } \\
\text { sobre o aluno }\end{array}$ & $\begin{array}{l}\text { "Não recebi nenhuma instrução, só explicaram sobre qual aluno seria, me } \\
\text { inforam que eu ficaria com um autista, recebi as informações do quadro } \\
\text { que crianha." }\end{array}$ \\
\hline
\end{tabular}

Fonte: Autores. 


\section{Conhecimentos sobre autismo}

No Quadro 3, observa-se o conteúdo dos discursos das professoras quando questionadas sobre o que entendiam por autismo. Diferentes discursos foram identificados, desde dificuldades em estabelecer uma definição a definições derivadas de uma linguagem técnica.

Quadro 3- Ideias Centrais e Discursos do Sujeito Coletivo referente à concepção de autismo da professora auxiliar, Foz do Iguaçu, PR, 2016

\begin{tabular}{|l|l|}
\hline \multicolumn{1}{|c|}{ IC } & \multicolumn{1}{c|}{ DSC } \\
\hline $\begin{array}{l}\text { Dificuldade de } \\
\text { definição }\end{array}$ & "Eu não sei definir para você. Eu realmente não tenho conhecimento." \\
\hline Definição técnica & $\begin{array}{l}\text { "Um transtorno global do desenvolvimento, uma síndrome, um } \\
\text { distúrbio neurológico." }\end{array}$ \\
\hline $\begin{array}{l}\text { Diferentes } \\
\text { características }\end{array}$ & $\begin{array}{l}\text { "Depende, tem diferença, depende do nível de comprometimento que } \\
\text { essa pessoa tem. Uma pessoa que tem autismo, ela não vai ser } \\
\text { exatamente como a outra, porque existem vários níveis. Antes se } \\
\text { flava síndrome de Asperger." }\end{array}$ \\
\hline $\begin{array}{l}\text { Dificuldades de } \\
\text { socialização }\end{array}$ & $\begin{array}{l}\text { "São muito fechados, precisam de confiança do outro, precisam } \\
\text { entender o processo de relacionamento, senão não se relacionam." }\end{array}$ \\
\hline $\begin{array}{l}\text { Inteligência com } \\
\text { dependência }\end{array}$ & $\begin{array}{l}\text { "É limitado, com algumas peculiaridades, mas inteligente. Só que se } \\
\text { você não ficar do lado dele, ele não faz nada." }\end{array}$ \\
\hline Estereotipia & "Ela tem algumas manias, possui alguns movimentos repetitivos." \\
\hline $\begin{array}{l}\text { Instabilidade } \\
\text { emocional }\end{array}$ & $\begin{array}{l}\text { "Eles ficam nervosos muito fácil, perdem o controle. Tem dia que eles } \\
\text { estão bem, estão num humor bom, mas tem dias que eles estão } \\
\text { incapacitados pra trabalhar [...]." }\end{array}$ \\
\hline $\begin{array}{l}\text { Sensibilidade } \\
\text { auditiva }\end{array}$ & "Problemas com barulho." \\
\hline
\end{tabular}

Fonte: Autores.

\section{Acesso a conhecimento e necessidades}

Outro item investigado com as professoras auxiliares foi onde ou a quem elas recorriam quando buscavam conhecimentos relativos ao autismo. A fonte mais mencionada foi a internet, através de vídeos, sites e textos, sem menção a artigos científicos ( $n=11)$.

Quando questionadas se consideram seus conhecimentos suficientes para trabalhar com um aluno autista, todas as professoras afirmaram que não, apresentando um DSC único para essa questão: "Com certeza não, considero meu conhecimento superficial pra trabalhar com ele. Eu tenho que estudar, aprender, ler...".

Em relação ao tipo de curso e conteúdos relacionados ao autismo que gostariam de ter acesso, os discursos variaram, desde professores que não souberam especificar o conteúdo ou que gostariam de informações básicas à solicitação de treinamento em métodos de ensino específicos e alternativos ou de manejo comportamental, conforme o disposto no Quadro 4. 
Quadro 4- Ideias Centrais e Discursos do Sujeito Coletivo referente ao tipo de cursos sobre autismo que as professoras auxiliar gostariam de ter acesso, Foz do Iguaçu, 2016

\begin{tabular}{|l|l|}
\hline \multicolumn{1}{|c|}{ IC } & \multicolumn{1}{c|}{ DSC } \\
\hline Genérico & $\begin{array}{l}\text { "Não tem assim um conteúdo específico, o que vier vai ser } \\
\text { bem vindo, não dá pra dizer nada específico". }\end{array}$ \\
\hline Informações básicas & $\begin{array}{l}\text { "Seria em relação a entender melhor o autismo, o } \\
\text { comportamento, a questão cognitiva... Antes era } \\
\text { Asperger, agora é autismo só que em níveis diferentes". }\end{array}$ \\
\hline $\begin{array}{l}\text { Treinamento com métodos } \\
\text { alternativos }\end{array}$ & $\begin{array}{l}\text { "Gostaria que tivesse cursos que transmitissem métodos } \\
\text { e materiais pra trabalhar com esses alunos. Como } \\
\text { trabalhar e organizar um currículo para que ele possa } \\
\text { acompanhar todas as disciplinas". }\end{array}$ \\
\hline Manejo comportamental & $\begin{array}{l}\text { "Seria interessante ter alguém que viesse falar mais } \\
\text { práticas para lidar com as crianças". }\end{array}$ \\
\hline
\end{tabular}

Fonte: Autores.

\section{Relação/planejamento com professor regente}

Também foi abordado com as professoras auxiliares sobre como era seu relacionamento profissional com o professor regente e o tipo de planejamento conjunto para o atendimento do aluno autista. O discurso mais frequente foi o de que não há um planejamento conjunto das atividades realizadas (Quadro 5).

Quadro 5- Ideias Centrais e Discursos do Sujeito Coletivo referente ao planejamento e convívio entre o professor regente e o professor auxiliar, Foz do Iguaçu, 2016

\begin{tabular}{|l|l|}
\hline \multicolumn{1}{|c|}{ IC } & \multicolumn{1}{c|}{ DSC } \\
\hline $\begin{array}{l}\text { Sem } \\
\text { planejamento }\end{array}$ & $\begin{array}{l}\text { "Planejamento não, nós não conseguimos montar um currículo } \\
\text { diferenciado, a gente troca ideias, opinião..." }\end{array}$ \\
\hline Há um acordo & "Ele(a) participa se tiver condições de participar, caso contrário não." \\
\hline $\begin{array}{l}\text { Relação } \\
\text { harmoniosa }\end{array}$ & $\begin{array}{l}\text { "É bem tranquila, tenho liberdade para trabalhar de uma maneira diferente } \\
\text { se necessário." }\end{array}$ \\
\hline $\begin{array}{l}\text { Relação } \\
\text { conflituosa }\end{array}$ & $\begin{array}{l}\text { "Às vezes a gente não concorda com a forma com que o professor do } \\
\text { ensino regular está conduzindo e isso causa divergências." }\end{array}$ \\
\hline
\end{tabular}

Fonte: Autores.

\section{Discussão}

\section{Caracterização, inserção e atuação das participantes}

Observa-se no município estudado a ausência de uma regulamentação específica para a atividade do professor auxiliar. Tal fato se verifica pela discrepância na formação desses profissionais, apesar de a maioria ter formação superior, especialização e mais de 10 anos de experiência docente. A inserção desses profissionais como professores auxiliares ocorreu, na maioria das vezes, por necessidade da escola e por falta de opção dos professores que estavam iniciando ou retomando suas atividades na instituição após afastamento. Apesar de uma nomenclatura distinta da encontrada na Lei Berenice Piana, 
publicada em 2012), a função exercida pelo professor auxiliar no município é a mesma apontada na lei pelo acompanhante especializado. Outras nomenclaturas encontradas para profissionais que exerciam essa função, encontradas ao longo do presente levantamento, foram: professor acompanhante, auxiliar pedagógico, acompanhante educacional, professor de apoio pedagógico, acompanhante terapêutico. Embora cada denominação possa denotar funções distintas, todos se referiam ao professor que acompanhava o aluno autista em sala regular, o que pode ser um indicativo da falta de clareza de quem deve ser esse profissional.

Tanto na Lei Berenice Piana (BRASIL, 2012) quanto no decreto que valida a atuação do acompanhante especializado (BRASIL, 2014) há a menção de que quando reconhecida a necessidade e solicitada a presença do acompanhante especializado é dever da instituição de ensino providenciá-lo. Apesar do termo "especializado", não há qualquer especificação se esse profissional deve ser um professor, nem qual deve ser a sua formação, nível de especialização exigida (se técnica, latu ou stricto sensu), ou tipo de experiência a ser comprovada. Tal imprecisão, além de gerar ambiguidade no momento de selecionar esses profissionais, dificulta à própria família do aluno autista fazer exigências no que tange à qualificação desses profissionais. Essas lacunas na legislação repercutem na diversidade de formação e na experiência dos professores no presente estudo, incluindo estagiários com idade inferior a 18 anos e em readequação funcional. A contratação de estagiários, profissionais temporários e com formação insuficiente para 0 cargo de acompanhante especializado também foi relatada nos estudos de Szymanski e Stepanha (2017), Silva e Silva (2016) e na revisão de Nunes, Azevedo e Schmidt (2013).

Da mesma maneira, o papel do acompanhante especializado não é propriamente descrito nos documentos oficiais, é mencionado que este deve ser providenciado pela instituição de ensino em caso de comprovada necessidade de apoio "às atividades de comunicação, interação social, locomoção, alimentação e cuidados pessoais" (BRASIL, 2014). Não há referência específica quanto às necessidades pedagógicas ou escolares, podendo o acompanhante ser alguém que meramente auxilie o aluno em alguma necessidade motora, sem necessidade de conhecimentos educacionais. Tal fator salienta o quão diversificada pode ser a atuação desse profissional, assim como as diferentes exigências que podem ser solicitadas. Deixa em aberto, também, sua finalidade, ficando a cargo da instituição de ensino que a estabeleça para cada profissional contratado. 
Osório, Gomes e Silva (2016) enfatizam que o papel do auxiliar não pode se restringir à assistência em tarefas diárias (como alimentação, ir ao banheiro, organização do material, dentre outros) e, sim, auxiliar diretamente na mediação da construção do conhecimento para a promoção de um desenvolvimento significativo, em que os alunos possam, além de ter interação social e se sentirem incluídos na sala de aula e na escola, aprender devidamente os conteúdos, atingindo os mesmos critérios educacionais planejados para os demais estudantes.

Salienta-se que mesmo as professoras com especialização em educação especial e mais tempo de experiência docente tiveram dificuldades para atuar como professoras auxiliares.

\section{Definição de TEA}

A pouca experiência com o transtorno demonstrada pela maioria das entrevistadas deste estudo se reflete na dificuldade que várias delas tiveram em conceituar o autismo e no fato de muitas conseguirem apenas falar a respeito do aluno ou aluna com quem estavam desenvolvendo suas atividades. Devido ao perfil dessas profissionais, sua atuação parece ocorrer de forma coadjuvante, lidando mais com o manejo comportamental do que com as devidas adaptações pedagógicas dos alunos com necessidades especiais, comprometendo assim a efetivação da inclusão desses alunos.

Dificuldade similar também foi corroborada por Szymanski e Stepanha (2017), comprovando o quanto a seleção desses profissionais não está condicionada aos seus conhecimentos sobre autismo. Destarte, é interessante constatar que as características descritas pelas participantes são compatíveis com as definições diagnósticas do autismo e com aspectos comportamentais comumente citadas na literatura (SCHMIDT, 2017): ampla variedade fenotípica e de comprometimentos, dificuldades de comunicação, estereotipias comportamentais, interesses restritos, dificuldades de manutenção da atenção, instabilidade comportamental com momentos de agressividade e sensibilidade sensorial auditiva ou tátil.

Um discurso que parece destoar da literatura referente ao autismo, embora não necessariamente incompatível com esta, foi que o aluno parecia apresentar inteligência acima da média da turma. Conforme Camargo e Bosa (2009), apenas 30\% dos casos de autismo são chamados de alto funcionamento e apresentam inteligência acima da média. Assim, essa constatação pode tanto ser derivada de: a) baixa expectativa em relação à 
capacidade cognitiva do aluno autista, similar ao encontrado na revisão de Schmidt et al. (2016); ou b) que a população escolar de autista seja composta de indivíduos com comprometimentos leves, enquanto casos mais severos não estejam tendo acesso ao ensino regular. A respeito dessa segunda hipótese, não foram encontrados dados oficiais para o município estudado ou índices nacionais; todavia, alguns estudos apontam para elevados índices de evasão escolar de alunos com autismo (LIMA; LAPLANE, 2016; TALARICO; LAPLANE, 2016) e dados da literatura internacional indicam que a população autista com baixo quociente de inteligência (QI) é sub-representada nas escolas (KEEN; WEBSTER; RIDLEY, 2016).

Independente da hipótese, essa afirmação está fortemente vinculada à experiência profissional da participante: sua bagagem de observação e vivência deve ter influenciado para essa opinião sobre o aluno ser mais inteligente ou não.

\section{Capacitação e busca por aprimoramento}

A necessidade de cursos, treinamentos e formação específica identificada no presente texto parece ser uma das questões mais recorrentes em estudos relativos a autismo (NUNES; AZEVEDO; SCHMIDT, 2013; SCHMIDT et al., 2016; CABRAL; MARIN, 2017). Na revisão de Cabral e Marin (2017), foi identificada a escassez de estratégias pedagógicas específicas para essa população tanto na literatura nacional quanto internacional, fator corroborado na revisão de Nascimento, Cruz e Braun (2017), os quais identificaram apenas seis artigos nacionais dedicados às práticas pedagógicas, a maioria de caráter avaliativo das práticas implementadas pelos investigados e não de novas propostas.

A falta de normativa específica sobre o professor auxiliar não impacta apenas na delegação de quem será esse profissional e na qualidade potencial dos serviços a serem prestados, mas também na determinação suas funções, suas metas educacionais, responsabilidades com o aluno autista e na própria delimitação do espaço e autonomia de sua atividade em relação à do professor regente. Sobre tais questões, verificou-se que quando chamados a trabalhar como professores auxiliares, poucas diretrizes eram fornecidas acerca da atividade a ser realizada, em geral, apenas recebiam informações sobre o aluno ou instruções genéricas. Tal fato indica que a própria instituição escolar não deve estar recebendo as adaptações e acompanhamento necessários e apenas fornece um profissional acompanhante por cumprimento de norma, sem o devido reconhecimento de seu papel e importância. 


\section{Relação interprofissional}

Observou-se ainda, pouco planejamento comum entre a professora auxiliar e o professor regente, o que resulta em situações de conflitos e desacordos entre esses profissionais e até da própria falta de reconhecimento do papel do professor auxiliar enquanto profissional, como ilustra a fala a seguir: "Às vezes o professor de apoio fica só como alguém que não quis sala de aula ou não está trabalhando, como se fosse uma pessoa que só está ali do lado" (participante P3). Ao entrevistar professores regulares sobre questões relacionadas à inclusão de alunos autistas, Szymanski e Stepanha (2017) também identificaram a falta de articulação e de delimitação das responsabilidades entre esses profissionais, enfatizando discursos nos quais o professor regente não se referia a si mesmo como professor do aluno autista. Mais uma vez, essa não parece ser uma particularidade do presente estudo ou nacional, Sharma e Salend (2016), ao revisarem a literatura em língua inglesa sobre o papel de auxiliares do professor regente em turmas inclusivas, identificaram problemas similares de falta de clareza do papel dos auxiliares e das fronteiras entre as duas atividades.

Algumas professoras relataram frustrações, conflitos profissionais, falta de apoio e de direcionamento para executar suas atividades. Também relataram interesse em buscar por conta própria formação específica em autismo e inclusão. Todas consideraram seus conhecimentos insuficientes para lidar com a educação de alunos autistas e embora estejam aprendendo sobre o autismo, afirmam que aceitariam continuar trabalhando como professor auxiliar.

\section{Considerações finais}

O professor auxiliar, ou acompanhante especializado, conforme sua denominação oficial (BRASIL, 2012), é uma categoria profissional recente; a própria diversidade de nomenclaturas encontradas nos discursos das professoras entrevistadas e na literatura consultada é um indicativo de seu processo de construção. Vale ressaltar que esta não é uma particularidade brasileira, a literatura internacional sobre o auxiliar do professor regente em salas de aula inclusiva é também permeada de uma variedade de denominações o que compromete a caracterização desse profissional e seu papel (GIANGRECO, 2013).

Muito se avançou nas políticas inclusivas e na legislação acerca desse profissional; acredita-se que o próximo passo deva ser a elaboração de diretrizes pontuais que 
diferenciem os diversos profissionais evolvidos e delimitem claramente seus papéis e metas específicas e conjuntas.

A colaboração da secretaria de educação do município estudado, das instituições de ensino e das participantes, mesmo em face às incertezas, limitações e dificuldades enfrentadas, é forte indício da carência desses profissionais e da disponibilidade em colaboração para implementação de práticas mais efetivas. Maior volume de estudos abrangentes sobre o tema é elemento fundamental para a elaboração conjunta de uma política nacional efetiva do papel do professor auxiliar e do aprimoramento da inclusão escolar de autistas.

Neste estudo, evidenciou-se o caráter ambíguo da função do professor auxiliar; por um lado, parece ser um cargo do qual os professores se esquivam, uma vez que em sua maioria foram "convocados" a atuar; por outro, é visto como um cargo de menor responsabilidade e exigência por se restringir ao atendimento de apenas uma criança. Tal esquiva, entretanto, não parece ser devida a essa avaliação negativa do cargo, e sim, de insegurança e falta de conhecimento a respeito do autismo, pois enquanto os entrevistados falavam sobre como se deu sua inserção como professoras auxiliares, eram frequentes relatos sobre o receio à atividade por terem ouvido histórias de instabilidade, agressividade e dificuldades por parte dos alunos.

É interessante notar que mesmo em face dos problemas destacados, um dos objetivos da inclusão parece estar sendo atingido: a quebra de preconceitos em relação ao autista, verificada pelo interesse dos profissionais entrevistados em continuar se aperfeiçoando nessa atividade.

Assinala-se que a inclusão escolar é um processo dinâmico e multifacetado, limitações e aspectos negativos não devem ser tomados como impeditivos. Do mesmo modo, aspectos positivos também não devem ser tomados como indício de que, mesmo em condições pouco favoráveis, as instituições educacionais e equipes pedagógicas acabam por encontrar seus caminhos e, então, pouco planejamento seja de fato necessário.

Diante dos dados obtidos neste estudo dentre as questões que poderiam ser aprimoradas destacam-se: a) realização de estudos sobre a incidência de autismo e estatísticas precisas relativas ao acesso à escola e evasão escolar desses indivíduos; b) maior oferta de cursos de capacitação para professores, com workshops de recursos 
pedagógicos específicos; c) acompanhamento e apoio aos profissionais envolvidos diretamente na inclusão, com criação de espaços de fala e compartilhamento de experiências; e d) criação de diretrizes específicas e claras da atuação de cada profissional envolvido no processo de inclusão.

\section{Referências}

APA. Manual diagnóstico e estatístico de transtornos mentais. Porto Alegre: Artmed, 2014.

BERTAZZO, Joíse de Brum. Acompanhamento escolar e transtornos do espectro do autismo. In: ANPED SUL, 10., 2014, Florianópolis. Anais Eletrônicos... Florianópolis: UDESC, 2014. Disponível em: http://xanpedsul.faed.udesc.br/arq_pdf/804-0.pdf. Acesso em: 05 nov. 2017.

BRASIL. Ministério da Educação. Secretaria de Educação Especial. Política nacional de educação especial na perspectiva da educação inclusiva. Brasília, DF, 2008.

BRASIL. Lei Federal no 12.764/2012, de 27 de dezembro de 2012. Institui a Política Nacional de Proteção dos Direitos da Pessoa com Transtorno do Espectro Autista; e altera o § 30 do art. 98 da Lei no 8.112, de 11 de dezembro de 1990. Brasília, DF: Diário Oficial da República Federativa do Brasil, 2012.

BRASIL.. Decreto Federal no 8.368/2014, de 02 de dezembro de 2014. Regulamenta a Lei no 12.764, de 27 de dezembro de 2012, que institui a Política Nacional de Proteção dos Direitos da Pessoa com Transtorno do Espectro Autista. Brasília, DF: Diário Oficial da República Federativa do Brasil, 2014.

BRASIL. Lei n. 9.394, de 20 de dezembro de 1996. Estabelece as diretrizes e bases da Educação Nacional. Diário Oficial da União, Brasília, DF, 23 dez. 1996.

CABRAL, Cristiane Soares; MARIN, Angela Helena. Inclusão escolar de crianças com transtorno do espectro autista: Uma revisão sistemática da literatura. Educação em Revista, Belo Horizonte, v. 33, p. e142079, 2017. 
CAMARGO, Síglia Pimentel Hoher; BOSA, Cleonice Alves. Competência social, inclusão escolar e autismo: revisão crítica da literatura. Psicologia \& Sociedade, Belo Horizonte, v. 21, n. 1, p. 65-74, 2009.

DIAS, Paulo C. A autoeficácia dos professores para a implementação de práticas inclusivas: contributos para uma reflexão sobre a inclusão educativa. Ensaio: Avaliação e Políticas Públicas na Educação (online). v. 25, n. 94, p. 7-25, 2017.

GIANGRECO, Michael F. Teacher assistant supports in inclusive schools: research, practices and alternatives. Australasian Journal of Special Education, Camberra, v. 37, n. 2, p. 93-106, 2013.

GOBBO, André; BONFIGLIO, Simone U.; SCHWARTZ, Lígia. O impacto da inclusão de síndromes graves na escola regular. In: BIEGING, P; BUSSARELLO, R. I.; ULBRICHT, V. R. (orgs.) Educação no plural: da sala de aula às tecnologias digitais. São Paulo: Pimenta Cultural, p. 218-241, 2016.

HAAS, Clarissa; PANTALEÃO, Edson; ORLANDO, Rosimeire Maria; BAPTISTA, Cláudio Roberto. Rodas de pesquisa e formação em educação especial: as trajetórias de estudantes com deficiência. Revista Brasileira Estudos Pedagógicos (on-line). Brasília, v. 97, n. 247, p. $570-582,2016$.

KEEN, Deb; WEBSTER, Amanda; RIDLEY, Greta. How well are children with autism spectrum disorder doing academically at school? An overview of the literature. Autism, London, v. 20, n. 3, p. 276-294, 2016.

LEFEVRE, Fernando; LEFEVRE, Ana Maria Cavalcanti. O sujeito coletivo que fala. Interface: Comunicação, Saúde, Educação. v. 10, n. 20, p. 517-524, 2006.

LEFEVRE, Fernando; LEFEVRE, Ana Maria Cavalcanti. Pesquisa de representação social um enfoque qualiquantitativo. 2. ed. Brasilia, DF: Liber Livro Editora, 2012.

LIMA, Stéfani Melo; LAPLANE, Adriana Lia Friszman de. Escolarização de alunos com autismo. Revista Brasileira de Educação Especial, Marília, v. 22, n. 2, p. 269-284, 2016. 
MALTERUD, Kirsti. Qualitative research: standarts, challenges and guidelines. The Lancet, v.358. p.483-488, 2001.

NASCIMENTO, Fabiana Ferreira do; CRUZ, Mara Monteiro da; BRAUN, Patricia. Escolarização de pessoas com transtorno do espectro do autismo a partir da análise da produção científica disponível na Scielo-Brasil (2005-2015). Arquivos Analíticos de Políticas Educativas, Tempe, v. 24, n. 125, 2017.

NUNES, D. R. P.; AZEVEDO, M. Q. O.; SCHIMIDT, C. Inclusão educacional de pessoas com Autismo no Brasil: uma revisão da literatura. Revista Educação Especial, Santa Maria, v.26, n.47, 557-572, 2013.

NUNES, Débora Regina de Paula; AZEVEDO, Mariana Queiroz Orrico; OSÓRIO, Regina Ribeiro de Paulo; GOMES, Vera Lúcia; SILVA, Rita de Fatima. O papel do auxiliar pedagógico especializado na inclusão do autista. Diálogos Interdisciplinares, Aquidauana, v. 1, n. 3, p. 50-65, 2016.

PADILHA, Ana Maria. Prefácio. In: MILANEZ, S. G. C.; OLIVEIRA, A. A. S.; MISQUIATTI, A. R. N. (orgs.) Atendimento educacional especializado para alunos com deficiência intelectual e transtornos globais do desenvolvimento. São Paulo: Cultura Acadêmica, p. 710, 2013.

SCHMIDT, Carlo. Inclusão educacional de pessoas com Autismo no Brasil: uma revisão da literatura. Revista Educação Especial, Santa Maria, v. 26, n. 47, p. 557-572, 2013.

SCHMIDT, Carlo; NUNES, Débora Regina de Paula; PEREIRA, Débora Mara; OLIVEIRA, Vivian Fátima de; NUERNBERG, Adriano Henrique; KUBASKI, Cristiane. Inclusão escolar e autismo: uma análise da percepção docente e práticas pedagógicas. Revista Psicologia: Teoria e Prática, São Paulo, v. 18, n. 1, p. 222-235, 2016.

SCHMIDT, Carlo. Transtorno do Espectro Autista: Onde estamos e para onde vamos. Psicologia em Estudo, Maringá, v. 22, n. 2, p. 221-230, 2017. 
SHARMA, Umesh; SALEND, Spencer J. Teaching Assistants in Inclusive Classrooms: A Systematic Analysis of the International Research. Australian Journal of Teacher Education, Joondalup, v. 41, n. 8, p. 118-134, 2016.

SILVA, Josenildo Pereira da; SILVA, Petrônio José da. Discente com autismo na sala de aula regular: o que fazer? Research, Society and Development, Itabira, v. 2, n. 2, p. $122-$ 135, 2016.

SZYMANSKI, Maria Lídia Sica; STEPANHA, Kelley Adriana de Oliveira. A apropriação docente do conceito de autismo e seus reflexos na prática pedagógica. In: Congresso Nacional de Educação EDUCERE, 13., 2017, Curitiba. Anais eletrônicos...Curitiba: PUC, 2017. Disponível em: http://educere.bruc.com.br/arquivo/pdf2017/26523_13645.pdf. Acesso em: 15 de nov. 2017.

TALARICO, Mariana Valente Teixeira da Silva; LAPLANE, Adriana Lia Friszman de. Trajetórias escolares de alunos com transtorno do espectro autista. Comunicações, Piracicaba, v. 23, n. 3, p. 43-56, 2016.

WARREN, Zachary; McPHEETERS, Melissa L.; SATHE, Nila; FOSS-FEIG, Jennifer H.; GLASSER, Allison; VEENSTRA-VANDERWEELE, Jeremy. A Systematic Review of Early Intensive Intervention for Autism Spectrum Disorders. Pediatrics, Estados Unidos, v. 127, n. 5, p. e1303-e1311, 2011.

\section{Correspondência}

Paulo César Morales Mayer - Universidade CEUMA. R. Barão do Rio Branco, 100 Entroncamento, Imperatriz. CEP: 65903-093. Imperatriz, Maranhão, Brasil.

This work is licensed under a Creative Commons Attribution-NonCommercial 4.0 International (CC BY-NC 4.0) 